\title{
The clinical features, diagnosis and management of recurrent thymoma
}

Taobo Luo ${ }^{1,2}$, Hongguang Zhao ${ }^{1,2,3^{*}}$ and Xinming Zhou ${ }^{1,2^{*}}$

\begin{abstract}
Thymoma is a disease with malignant potential, which has a recurrence rate after complete resection ranging from 5 to $50 \%$. Multiple studies on the risk factors, treatment or prognosis have been reported. Many of them are controversial, however. In this review, we summarized some accepted risk factors, means of diagnosis and different treatments of recurrent thymoma. The risk factors of recurrent thymoma haven't been well-studied, and its management remains controversial. We reviewed the literatures and found some key points which should be noticed during the surgery of initial thymoma. Although reoperation should be taken into account preferentially, multimodal treatments are also available. The prognosis are also been discussed.

Keywords: Thymoma, Recurrence, Risk factor, Diagnosis, Treatment, Prognosis

Abbreviations: $\mathrm{CT}$, Computerized tomographic; DNA, Deoxyribonucleic acid; ECT, Emission computed tomography; EGFR, Epidermal Growth Factor Receptor; IFN, Interferon; IL, Interleukin; ITMIG, International Thymic Malignancy Interest Group; JART, Japanese Association for Research on Thymus; MRI, Magnetic resonance imaging; PET$\mathrm{CT}$, Positron emission tomography; VATS, Video assisted thoracic surgery; WHO, World Health Organization
\end{abstract}

\section{Background}

Thymoma is a disease with malignant potential, which shows a possibility of recurrence after complete resection. The International Thymic Malignancy Interest Group (ITMIG) has recently defined a standard set of definitions for recurrence [1]: (1) the term 'recurrence' is appropriate if all disease has been potentially eradicated (R0 resection); (2) recurrences are classified as local (anterior mediastinum), regional (intrathoracic not contiguous with the thymus), and distant (intrapulmonary and extrathoracic); and (3) the freedom-from- recurrence outcome indicator should be used for any study on recurrence after R0 resection, and 5- and 10-year outcomes should be reported in every series.

The recurrence of thymoma is rare, the rate ranges according to different reports. In the research of Japanese Association for Research on Thymus (JART), among all the 2835 thymoma patients received operation during 1991-2010, 420 (14.8 \%) experienced recurrence [2]. The average disease-free time of recurrent patients was 5 years, and recurrence occurred 32 years after initial operation was also reported [3]. The time to relapse was 10 years for patient of clinical stage I, and 3 years for patient of stage II, III and IV.

Most recurrence are local and regional [4, 5]. 46-80 \% of recurrent cases are found in the thoracic cavity [5-7], and then in the mediastinum and lungs $[2,8]$, distant metastases occur in less than $5 \%$ of the cases [9]. In the report of Detterbeck et al. [10], Among patients with recurrences, the pleural space or the lung was involved in $58 \%$ (most often as a nodule under the parietal pleura), the pericardium or mediastinum in $41 \%$, bone in $10 \%$, and liver in $8 \%$.

According to the study of The Japanese Association for Chest Surgery [11], of 862 patients who had information, 67 (7.8 \%) developed recurrence. The recurrence rates in stages I, II, III, and IV were 0.9, 4.1, 28.4, and $34.3 \%$, respectively; In thymic carcinoma, $51 \%$ of patients developed recurrence, whereas, in thymic carcinoid, $64 \%$ of patients had recurrence.

\footnotetext{
*Correspondence: zhao_hg75@hotmail.com; zxm_zj@sina.com

'Department of Thoracic Surgery, Zhejiang Cancer Hospital, Hangzhou

310022, People's Republic of China

Full list of author information is available at the end of the article
} 


\section{The risk factors of recurrent thymoma Masaoka classification}

The Masaoka classification was one of the well-accepted risk factors of thymoma recurrent. Tumors capsulated and not infiltrated with neighbor tissue or organs recur very rarely (0 to $5 \%$ ) [12]; invasive tumors show a recurrence rate ranging from 20 to $50 \%$ from stage 1 to stage $4 \mathrm{a}$, respectively $[11,13]$. Most stage I and II thymomas recur locally or regionally [14]. The majority of the recurrent patients had advanced disease of stage III or IV $(n=329 ; 81.2 \%)$ [2]. Some researchers believe that the invasion of major blood vessel (stage IIIb) strongly suggest tumor recurrence [15]. The more advance Masaoka stage is, the more possible remote recurrence happens.

\section{World Health Organization histology}

The recurrence of thymoma is closely related to its World Health Organization (WHO) histology. It is reported that few patients of type A/AB thymoma experience recurrence, when the recurrent rate was $28.6 \%$ and over $50 \%$ for patients with type B and type C thymoma, respectively [11]. The recurrence of type $C$ thymoma is quicker and more frequent than the other types; its metastasis is also much common [16, 17]. Wright et al. [7] raised a point of view that if divide thymoma among four groups (A/AB, B1/B2, B3 and $\mathrm{C}$ ) according to WHO histology, its rate of local invasion and recurrence rises one by one. The recurrent rate of type $\mathrm{C}$ thymoma is several times higher than the others ( $41 \%$ vs $9.7 \%$ ) [17]. There is some relationship between the WHO histology and Masaoka classification of thymoma, as most type A and type B thymoma are at stage I and stage II, and type B2/B3/C thymoma are usually at stage III and stage IV [8].

\section{Other risk factors}

Incomplete initial resection is regarded as one of the risk factors of recurrence. Taken the possibility of ectopic and vagus thymus into consideration, a synchronous tumor resection and clean-up of the fat tissue in anterior mediastinum is helpful to avoid the recurrence of thymoma, in spite of the tumor's volume and the integrity of its envelope $[18,19]$. The method of initial operation may also be a risk factor. Some researchers raised concern about whether minimally invasive (Video assisted thoracic surgery or Da Vinci robot) methods is prone to induce recurrence $[20,21]$, but recent reports indicated that there isn't significant difference between minimally invasive surgery and traditional open operation for experienced surgeons [22, 23]. In case of thymomas greater than $2 \mathrm{~cm}$ and without fat tissue surrounding the thymic capsule, the manipulation of the tumor may cause seeding of tumor cells that are responsible for local and pleural recurrences [16]. Recurrence may occur within the thymus left in place during the first surgical procedure or in the thoracic compartment where thymoma was located, in the pleural space opened to allow complete resection, and even at the site of the wound of the first operation or the mediastinal biopsy initially performed for tissue diagnosis [24], which suggests the risk of implantation metastasis during the operation. Other researchers find that tumor larger than $8 \mathrm{~cm}$ is also a risk factor of recurrence [7, 25]. Otherwise, studies on the molecular biology discover that DNA aneuploidy, IFN- $\alpha$ and IL-12 are also helpful in predicting the recurrence of thymoma [26-28].

\section{The diagnosis of recurrent thymoma Symptoms}

The recurrence of thymoma is usually insidious, most patients have no complains [29]. Myasthenia gravis is most common among all the symptoms, which may appear on more than half of the patients $[17,30]$. One patient who shows the symptom of myasthenia gravis induced by the initial thymoma, may be also caught by it when tumor recurrent [31]. In addition, some patients could have oppress symptoms such as chest pain and dyspnea, which are like initial thymoma.

\section{Computerized tomographic scanning}

Computerized tomographic scanning (CT) is the routine examination for patients after initial tumor resection, and is also the main way to screen recurrence thymoma. A research shows that $94 \%$ of asymptomatic patients found the mass by CT [32]. If myasthenia gravis or other symptoms arises, CT could be the first choice. However, $\mathrm{CT}$ is a morphological examination; and local tissue adhesion, fibrillation and scarring induced by surgery or post-surgery radiotherapy may harass the interpretation of CT images.

\section{Positron emission tomography}

Positron emission tomography (PET-CT) could make up the shortness of CT by measuring the metabolic rate of tissue, which improve the accuracy of diagnosis. CT overall sensitivity for detecting the mediastinal recurrence and pleural dissemination of thymomas is $71 \%$, and its specificity is $85 \%$; as for PET/CT, the overall sensitivity and specificity for thymoma recurrence are 82 and $95 \%$, respectively [33]. When employed for the diagnosis of thymoma recurrence in the anterior mediastinum, the sensitivity of PET-CT has reached $100 \%$, when CT is only $55 \%$ [33]. Besides that, the metabolic rate of tissue showed by PET-CT is related to the grade of malignancy of recurrent thymoma [34]. PET-CT may even help to classify the World Health Organization histology of recurrent thymoma [35]. Nevertheless, the recurrence thymoma on the pleura usually appears as 
multiple nodules in the image of PET-CT, and the calculation of metabolic rate is difficult because of partial volume effect [36].

\section{Others}

Magnetic resonance imaging (MRI) is a means with low radiation dose, and is better at representing cystic tissue than CT; MRI also has an advantage in differentiating thymic hyperplasia and thymoma, even evaluating whether the phrenicus nerve is infiltrated [37]. Literature states that ECT shows increased uptake of Tc-99 $\mathrm{m}$ in the primary and recurrent thymoma [38], which indicates ECT may be useful in the diagnosis.

\section{Pathology}

Pathology is the gold standard of tumor diagnosis, which consists cytopathology and histopathology. As in most cases, the tumor locates in the anterior mediastinal, sheltered by sternum and surrounded by main vessels, so the puncture guided by $\mathrm{CT}$ or ultrasound could be performed only if the tumor spreads out of the sternum. Histopathology could be performed through mediastinoscope, thoracoscope or open surgery.

\section{The prevent of recurrent thymoma}

\section{In the operation}

The principle of tumor-free is crucial for the prevention of local and regional prevention. Complete resection of the entire thymus is recommended, along with extreme care during dissection and en bloc resection of the surrounding structures infiltrated by the tumor [8]. Blockade of the tumor surface could reduce the risk of tumor implantation metastasis.

Most recurrence are found pleural recurrence, it is not clear whether they are related to the particular biology of the tumor or whether they are consequences of seeding of the tumor, possibly determined by disruption of the capsule during the operation. For this reason, some surgeons recommend to avoid opening the mediastinal pleura and avoid miniinvasive procedures with a transpleural approach (thoracotomy, VATS, or robot assisted) [14, 15].

\section{Postoperative}

As quite a bit of recurrent thymoma are in the mediastinum, so there are viewpoints that mediastinal radiation after initial operation are effective in reducing the recurrent rate [6]. However, subsequent reports showed that adjuvant radiotherapy was associated with late morbidity to the heart, lungs, and other mediastinal structures [39-41]; the cost of radiation therapy is sometimes higher than surgery, and mediastinal radiation does not prevent pleural implants, which represents the most common pattern of recurrence [8], so selective use of radiation therapy was suggested.
Currently, adjuvant radiotherapy is not indicated for stage I thymoma, as it's easy to achieve R0 resection, and histology is usually type A or B1 [11, 42, 43], the recurrence rate is almost $0[42,44]$. Adjuvant radiotherapy does not add any advantage for stage II thymoma which is completely resected; and it might be indicated for type B2/B3 lesions [45, 46]. Thus, adjuvant radiotherapy should be reserved in case of close proximity of the tumor to the resection margins or extracapsular involvement of the mediastinal fat or presence of adhesions to the pericardium and mediastinal pleura [8]. Multiple researches show adjuvant radiotherapy makes no benefit for stage III thymoma [11, 42, 47]. Adjuvant radiotherapy should be considered for patients receiving incomplete resection or with suspected involvement of the surgical margins, or with type B2/B3 histology or in case of previous open biopsy that could contribute to contaminate the surgical wound [8]. Besides, some authors suggest a potential role for postoperative chemotherapy, as most recurrence of stage III thymoma are within the pleura [47]. Stage IV patients generally received adjuvant mediastinal radiation therapy, which cannot prevent pleural or pulmonary metastases but may prevent mediastinal recurrence [5]. Surgical removal followed by intrapleural hyperthermic chemotherapy is another treatment strategy [48].

\section{Follow-up}

Patients with incomplete resections and patients with thymic carcinoma are recommended for more frequent (computed tomographic surveillance every 6 months) follow-up during the first 3 years given their higher propensity for relapse [49]. An annual chest CT within 5 years after thymoma resection and biannual chest CTs after 5 years for at least 20 years are recommended [32].

\section{The treatment of recurrent thymoma}

Once the thymoma is relapse, the effect of treatment may not be ideal. As the initial operation usually resect all the thymus and fat tissue in the mediastinum, expose vessels and nerves, so the re-operation is quite risky and difficult. Reducing-tumor operation plus hyperthermia perfusion chemotherapy may be a good choice [50].

Recurrent thymoma is malignant, and multimodal treatment is necessary. Thymoma is a slow glowing tumor, patient may get a long survival without any treatment. Supportive treatment may be the best choice for those who have a low PS score and couldn't tolerant further treatment.

\section{Surgery}

Most doctors regard surgery as the first choice for patients of recurrent thymoma. The average rates of 5- and 10-year overall survival after recurrence in patients 
treated surgically were $70.9-82.7 \%$ and $49.6-68.2 \%$, and in patients treated nonsurgically, they were 29.6$43.5 \%$ and $18.4-25.4 \%$, respectively $[3,4,51]$. The patients of recurrent thymoma who receive operation have an obvious better overall survival rate than those treated with chemotherapy only [5, 12, 52-55]. Some researchers raised an issue that the operation should be performed as long as the tumor is resectable and the patient could sustain the surgery [29]. Other opinions propose that surgical resection should be considered in patients with a localized recurrence after apparently successful initial therapy; in some patients with stage IV disease, the resection of isolated pleural metastases is an appropriate initial approach; for cases with multiple pleural metastases, chemotherapy, with or without subsequent surgery, is often appropriate [56]. The operative mortality was reported ranging from 0 to $13.3 \%$, and the operative morbidity ranging from 0 to $32.1 \%$; most patients suffering from operative mortality and morbidity had myasthenia gravis [57]. So it seems necessary to control myasthenia gravis with drugs pre-operative.

For patients with single pleural recurrences, a partial resection is necessary [16]. Sometimes pleural recurrences are extensive, with huge pleural implants infiltrating the lung and the diaphragm; in such cases, an extended pleuropneumonectomy may be the only chance to attempt radicality [58]. Strict selection criteria for such an aggressive treatment include young age, excellent cardiopulmonary function, and absence of metastatic disease using PET-CT [8]. The type of surgical approach depends upon the site and side of the recurrence, the associated surgical risks for bone infection, and the surgeon's preference. Pleural recurrences are approached best by means of thoracotomy, although recent reports indicate that sternotomy may be performed; mediastinal recurrence usually is approached by means of median sternotomy. The combination of median sternotomy and anterior thoracotomy may improve exposure of the mediastinum and the ipsilateral hemithorax [8].

Hamaji et al. [17] believe that repeat surgical resection alone has a limited role in the management of recurrent type $\mathrm{C}$ thymoma and thymic carcinoid given the higher rate of relapse, earlier relapses, more distant metastases, and lower overall survival and progression-free interval. Other contraindications include: unilateral pleural recurrence with extensive lesions, bilateral pleural recurrence, early recurrence, bilateral pulmonary recurrence, cervical lymph nodes metastasis, extrathoracic recurrence and poor general condition [32].

\section{Radiotherapy}

In nonresectable local recurrences, exclusive radiotherapy has been reported as an efficient treatment, especially on pleural recurrences, even if irradiation had previously been delivered. High response rates with 5 -year survival rates as high as $80 \%$ were obtained in small retrospective series. [53].

\section{Chemotherapy}

Many literatures suggest chemotherapy as the best choice for nonresectable recurrent thymoma [52, 59, 60]. However, there isn't a well-accepted chemotherapy regiment yet. Generally, type C thymoma has the worst sensitivity [61].

Cisplatinum combined with anthracycline is the most popular chemotherapy regiment [62-64]. Taxol is not so effective, but could be the drug of second-line [61] Besides, cyclophosphamide [63], pemetrexed [65, 66], gemcitabine combined with capecitabine [67] may also help relieve the tumor progression.

An attractive treatment of the pleural implants of thymoma is hyperthermic intrapleural chemotherapy. Circulation of cisplatinum $(100 \mathrm{mg} / \mathrm{m} 2)$ flows of 1000 to $2000 \mathrm{~mL} / \mathrm{min}$ with an inflow temperature of $42{ }^{\circ} \mathrm{C}$ or higher were required to maintain the desired temperature, $79 \%$ of the patients have had complete local control for periods ranging from 10 to 70 months [48]. Cisplatinum combined with adriamycin or doxorubicin are also effective $[68,69]$.

\section{Targeted therapy}

In recent years, researches on the targeted therapy of recurrent thymoma have started. Epidermal Growth Factor Receptor (EGFR) has a high expression in the cells of thymoma, but mutations are rare, so EGFR tyrosine kinase inhibitors may not be effective. A case report shows that a patient with EGFR mutation fails to respond to gefitinib [70]. However, some EGFR strong positive patients achieve partial remission after treated with cetuximab $[71,72]$.

Bevacizumab was tested in combination with erlotinib, no tumor response was observed, but stable disease rate was $60 \%$ [73]. $14 \%$ patients could achieve a partial response when treated with cixutumumab, and $76 \%$ have stable disease [74]. $8 \%$ patients achieve partial response under the treatment of histone deacetylase inhibitor Belinostat, and the two-year overall survival rate is $77 \%$ [75].

Somatostatin receptors are expressed in a variety of malignancies including thymic epithelial tumors, so octreotide is regarded as an alternative for recurrent thymoma [76]. In patients whose tumor is octreotidereactive and treated with octreotide or octreotide combined with prednisone, $28.5-30.3 \%$ show disease response, $35.7-36.8 \%$ have stable disease $[77,78]$.

\section{Multimodal treatments}

As the initial operation damaged the original anatomical structure, induced local adhesions, and recurrent thymoma is prone to invade main vessels and nerves, so 
secondary operation is difficult to achieve radical cure, the rate of R0 resection is only $50-60 \%[8,12,24]$. So, post-operative multimodal treatments are necessary for many patients with recurrence. Several researches show that operation followed by other treatments could improve prognosis [17, 49, 79-81]. However, only a small part of patients received treatment after operation (20.4 \% for chemotherapy and $20.9 \%$ for radiotherapy) [4]. People have not reach an agreement about the therapeutic regimen yet, and relevant studies are few.

Operation doesn't achieve R0 resection is regarded as the indication for post-operative adjuvant radiotherapy [17]. The mostly accepted indications to adjuvant radiotherapy are: resection performed macroscopically or microscopically not radical, particularly in case of thymomas, peeled off the phrenic nerve or great vessels; in case of any doubts about radicality of the resection, type $\mathrm{B} 2 / 3$, because it is more aggressive; in case of biopsies through mediastinotomy [16].

Shin et al. [82] revealed an aggressive but highly effective multimodal treatment for locally advanced, unresectable thymoma: induction chemotherapy (three courses of cyclophosphamide, doxolubicin, cisplatin, and prodnisone), surgical resection, postoperative radiation therapy, and consolidation chemotherapy. This multidisciplinary approach may increase the effect of re-operation and elevate their survival rate.

Percutaneous cryoablation is available for patients with pleural recurrence [83]. Other studies show cortisol alone or with tacrolimus is effective for recurrent thymoma [84-86].

\section{Clinical concerns of recurrent thymoma}

The recurrence is of importance to patients of thymoma. The effect of treatment for recurrent thymoma is not as good as primary tumor, and the prognosis is not good. As the recurrent thymoma is relatively rare $[2,11]$, and disease-free time varies, it is difficult to carry out clinical trial. There are still some clinical concerns about recurrent thymoma.

It's important and difficult to tell which patients are likely to experience recurrence and prevent the recurrence. Establishing an evaluation system of the recurrent risk is necessary. Patients of high recurrent risk may obtain a benefit through neoadjuvant and adjuvant therapy, including radiotherapy, chemotherapy and targeted therapy. To those who are prone to get recurrent disease, a more frequent than mentioned above [49] maybe meaningful for early intervention.

Many doctors may concern how to achieve the early diagnosis of recurrent thymoma. As there is tissue adhesion, fibrillation and scarring induced by the resection of primary tumor, it may be difficult to diagnose the recurrence by traditional imageological examination. The low recurrent rate and lack of experience is another negative factor. PET-CT shows an advantage in the diagnosis of recurrent thymoma [33, 35]. Its application is limited by the cost, however. Formulating a criteria for the diagnosis is of importance to recurrent thymoma.

Recurrence is an important aspect of thymoma. As there are still concerns about the prevention, diagnosis and management of recurrent thymoma, randomized clinical trials of multi-center is necessary. International collaboration should be encouraged.

\section{The prognosis of recurrent thymoma}

The 5-year and 10-year survival rates are 51-59.9 \% and $42.5-43 \%[2,5]$; and those of type C thymoma patients are 30.8 and $28.2 \%$ [2]. The 5-year survival rate following complete resection is $64-80 \%[43,44]$. Masaoka classification, WHO histology type and complete resection are main factors affecting the prognosis [29, 44, 87]. Early recurrence ( $<40$ months) is known as a negative prognostic factor [15], and local recurrence, single recurrence both imply better prognosis [21, 32, 88]. Regarding the patients with single-site recurrence, the 5- and 10year survival rates of the patients with pleural dissemination are 90.6 and $66.9 \%$, which indicate a trend toward a more favorable survival compared with that observed in the patients with recurrence at the other sites [2].

\section{Conclusion}

Recurrent thymoma is rare disease, differences between patients are obvious. It's difficult to evaluate the regiment of multimodal treatments. Controversy about the management of recurrent thymoma still exists. Multicenter prospective clinical trials with large sample are necessary to provide evidence for making the strategy of managing recurrent thymoma.

\section{Acknowledgements \\ Not applicable. \\ Funding \\ This review was not funded by any companies or groups.}

Availability of data and materials

Not applicable.

\section{Authors' contributions}

$T L$ and $H Z$ reviewed literature, collected data and wrote the manuscript. XZ critically reviewed anaesthetic literature. All authors read and approved the final manuscript.

\section{Competing interests}

The authors declare that they have no competing interests.

\section{Consent for publication}

Not applicable.

Ethics approval and consent to participate Not applicable. 


\section{Author details}

'Department of Thoracic Surgery, Zhejiang Cancer Hospital, Hangzhou 310022, People's Republic of China. ${ }^{2}$ Wenzhou Medical University, Wenzhou 325035, People's Republic of China. ${ }^{3}$ Zhejiang Key Laboratory of Diagnosis and Treatment Technology on Thoracic Oncology (Lung and Esophagus), Zhejiang Cancer Hospital, Hangzhou 310022, People's Republic of China.

\section{Received: 23 March 2016 Accepted: 23 August 2016}

\section{Published online: 31 August 2016}

\section{References}

1. Detterbeck F. International thymic malignancies interest group: a way forward. J Thorac Oncol. 2010;5(10 Suppl 4):S365-70.

2. Mizuno T, Okumura M, Asamura H, Japanese Association for Research on Thymus, et al. Surgical management of recurrent thymic epithelial tumors a retrospective analysis based on the Japanese nationwide database. J Thorac Oncol. 2015;10(1):199-205.

3. Awad WI, Symmans PJ, Dussek JE. Recurrence of stage I thymoma 32 years after total excision. Ann Thorac Surg. 1998:66(6):2106-8.

4. Hamaji M, Ali SO, Burt BM. A meta-analysis of surgical versus nonsurgical management of recurrent thymoma. Ann Thorac Surg. 2014;98(2):748-55.

5. Huang J, Rizk NP, Travis WD, et al. Comparison of patterns of relapse in thymic carcinoma and thymoma. J Thorac Cardiovasc Surg. 2009;138(1):26-31.

6. Muller-Hermelink HK, Strobel P, Zettl A, et al. Combined thymic epithelial tumors. In: Travis WD, Brambilla E, Muller-Hermelink HK, Harris CC, editors. Pathology and genetics: tumours of the lung, pleura, thymus and heart (WHO classification of tumours). Lyon: IARC Press; 2004. p. 196-201.

7. Wright $C D$, Wain $J C$, Wong $D R$, et al. Predictors of recurrence in thymic tumors: importance of invasion, World Health Organization histology, and size. J Thorac Cardiovasc Surg. 2005;130(5):1413-21.

8. Ruffini E, Filosso PL, Oliaro A. The role of surgery in recurrent thymic tumors. Thorac Surg Clin. 2009;19(1):121-31

9. Venuta F, Rendina EA, Longo F, et al. Long-term outcome after multimodality treatment for stage III thymic tumors. Ann Thorac Surg. 2003;76(6):1866-72.

10. Detterbeck FC, Parsons AM. Thymic tumors. Ann Thorac Surg. 2004;77(5):1860-9.

11. Kondo $\mathrm{K}$, Monden $\mathrm{Y}$. Therapy for thymic epithelial tumors: a clinical study of 1,320 patients from Japan. Ann Thorac Surg. 2003;76(3):878-84.

12. Ruffini E, Mancuso M, Oliaro A, et al. Recurrence of thymoma: analysis of clinicopathologic features, treatment, and outcome. J Thorac Cardiovasc Surg. 1997;113(1):55-63.

13. Pearson FG. Thoracic surgery. Philadelphia: Churchill Livingstone; 2002.

14. Ciccone AM, Rendina EA. Treatment of recurrent thymic tumors. Semin Thorac Cardiovasc Surg. 2005;17(1):27-31.

15. Blumberg $D$, Port $J L$, Weksler $B$, et al. Thymoma: a multivariate analysis of factors predicting survival. Ann Thorac Surg. 1995;60(4):908-13.

16. Lucchi M, Mussi A. Surgical treatment of recurrent thymomas. J Thorac Oncol. 2010:5(10 Suppl 4):S348-51.

17. Hamaji M, Allen MS, Cassivi SD, et al. The role of surgical management in recurrent thymic tumors. Ann Thorac Surg. 2012;94(1):247-54.

18. Safieddine N, Liu G, Cuningham K, et al. Prognostic factors for cure, recurrence and long-term survival after surgical resection of thymoma. J Thorac Oncol. 2014;9(7):1018-22.

19. Juel VC. Myasthenia gravis management of mysthenic ctisis and perioperative care. Semin Neurol. 2004;24(1):75-81.

20. Bodner J, Wykypiel H, Greiner A, et al. Early experience with robot-assisted surgery for mediastinal masses. Ann Thorac Surg. 2004;78(1):259-65.

21. Lucchi M, Basolo F, Mussi A. Surgical treatment of pleural recurrence from thymoma. Eur J Cardiothorac Surg. 2008:33(4):707-11.

22. Ye B, Tantai JC, Ge XX, et al. Surgical techniques for early-stage thymoma: video-assisted thoracoscopic thymectomy versus transsternal thymectomy. J Thorac Cardiovasc Surg. 2014;147(5):1599-603.

23. Augustin F, Schmid T, Sieb M, et al. Video-assisted thoracoscopic surgery versus robotic-assisted thoracoscopic surgery thymectomy. Ann Thorac Surg. 2008:85(2):S768-71

24. Regnard JF, Zinzindohoue F, Magdeleinat $P$, et al. Results of reresection for recurrent thymomas. Ann Thorac Surg. 1997;64(6):1593-8.

25. Xu C, Feng QF, Fan CC, et al. Patterns and predictors of recurrence after radical resection of thymoma. Radiother Oncol. 2015;115(1):30-4.

26. Davies SE, Macartney JC, Camplejohn RS, et al. DNA flow cytometry of thymomas. Histopathology. 1989;15(1):77-83.
27. Buckley C, Newsom-Davis J, Willcox N, et al. Do titin and cytokine antibodies in MG patients predict thymoma or thymoma recurrence? Neurology. 2001;57(9):1579-82.

28. Sasaki $\mathrm{H}$, Yukiue $\mathrm{H}$, Kobayashi $Y$, et al. Elevated serum pro-MMP2 levels in patients with stage IV thymoma. Surg Today. 2002;32(6):482-6.

29. Filippo L, Alfredo C, Stefano M, et al. Caveats in recurrent thymoma management. J Thorac Oncol. 2012;7(8):1207-8.

30. Haniuda M, Kondo R, Numanami H, et al. Recurrence of thymoma clinicopathological features, re-operation, and outcome. J Surg Oncol. 2001;78(3):183-8.

31. Margaritora S, Cesario A, Cusumano G, et al. Single-centre 40-year results of redo operation for recurrent thymomas. Eur J Cardiothorac Surg. 2011;40(4):894-900.

32. Bae MK, Byun CS, Lee CY, et al. Clinical outcomes and prognosis of recurrent thymoma management. J Thorac Oncol. 2012;7(8):1304-14.

33. El-Bawab HY, Abouzied MM, Rafay MA, et al. Clinical use of combined positron emission tomography and computed tomography in thymoma recurrence. Interact Cardiovasc Thorac Surg. 2010;11(4):395-9.

34. Kubota K, Yamada S, Kondo T, et al. PET imaging of primary mediastinal tumors. Br J Cancer. 1996:73:882-6.

35. Ito H, Shimada K, Isogami $\mathrm{K}$, et al. Recurrent thymoma radiological ( $C \mathrm{C}$ and FDG-PET) and histological (WHO criteria) features. Radiat Med. 2006;24(4):292-6.

36. Jung KJ, Lee KS, Han J, et al. Malignant thymic epithelial tumors: CT—pathologic correlation. AJR Am J Roentgenol. 2001;176(2):433-9.

37. Carter BW, Benveniste MF, Truong MT, et al. State of the art: MR imaging of thymoma. Magn Reson Imaging Clin N Am. 2015;23(2):165-77.

38. Kim SJ, Kim IJ, Kim YK. Tc-99m MIBI, Tc-99m tetrofosmin, and Tc-99m (V) DMSA accumulation in recurrent malignant thymoma. Clin Nucl Med. 2002:27(1):30-3.

39. Kleikamp G, Schnepper U, Korfer R. Coronary artery disease and aortic valve disease as a long-term sequel of mediastinal and thoracic irradiation. Thorac Cardiovasc Surg. 1997:45(1):27-31.

40. Shulimzon T, Apter S, Weitzen R, et al. Radiation pneumonitis complicating mediastinal radiotherapy postpneumonectomy. Eur Respir J. 1996;9(12):2697-9.

41. Yeoh E, Holloway RH, Russo A, et al. Effects of mediastinal irradiation on esophageal function. Gut. 1996;38(2):166-70.

42. Singhal S, Shrager JB, Rosenthal DI, et al. Comparison of stages: thymoma-treated complete resection with or without adjuvant radiation. Ann Thorac Surg. 2003:76(5):1635-41.

43. Quintanilla-Martinez L, Wilkins Jr EW, Choi N, et al. Thymoma. Histologic subclassification is an independent prognostic factor. Cancer. 1994;74(2):606-17.

44. Wright CD. Management of thymomas. Crit Rev Oncol Hematol. 2008;65(2):109-20.

45. OgawaK UT, Toita T, et al. Postoperative radiotherapy for patients with completely resected thymoma. Cancer. 2002;94:1405-13.

46. Rena O, Papalia E, Oliaro A, et al. Does adjuvant radiation therapy improve disease-free survival in completely resected Masaoka stage II thymoma? Eur J Cardiothorac Surg. 2007;31(1):109-13.

47. Mangi AA, Wain JC, Donahue DM, et al. Adjuvant radiation of stage III thymoma: is it necessary? Ann Thorac Surg. 2005;79(6):1834-9.

48. Refaely $Y$, Simansky DA, Paley $M$, et al. Resection and perfusion thermochemotherapy: a new approach for the treatment of thymic malignancies with pleural spread. Ann Thorac Surg. 2001;72(2):366-70.

49. Bott MJ, Wang H, Travis W, et al. Management and outcomes of relapse after treatment for thymoma and thymic carcinoma. Ann Thorac Surg. 2011:92(6):1984-91.

50. de Bree E, van Ruth S, Rutgers EJ, et al. Reoperation combined with intraoperative hyperthermic intrathoracic perfusion chemotherapy for pleural recurrence of thymoma. J Surg Oncol. 2002;80(4):224-5.

51. Maggi G, Casadio C, Cavallo A, et al. Thymoma: results of 241 operated cases. Ann Thorac Surg. 1991;51(1):152-6.

52. Vita ML, Tessitore A, Cusumano G, et al. Recurrence of thymoma: reoperation and outcome. Ann Ital Chir. 2007;78(5):375-6.

53. Urgesi A, Monetti U, Rossi G, et al. Aggressive treatment of intrathoracic recurrences of thymoma. Radiother Oncol. 1992;24(4):221-5.

54. Sandri A, Cusumano G, Lococo F, et al. Long-term results after treatment for recurrent thymoma a multicenter analysis. J Thorac Oncol. 2014;9(12):1796-804.

55. Okumura $\mathrm{M}$, Shiono $\mathrm{H}$, Inoue $\mathrm{M}$, et al. Outcome of surgical treatment for recurrent thymic epithelial tumors with reference to world health organization histologic classification system. J Surg Oncol. 2007;95(1):40-4.

56. Falkson CB, Bezjak A, Darling G, et al. The management of thymoma: a systematic review and practice guideline. J Thorac Oncol. 2009;4(7):911-9. 
57. Dai J, Song N, Yang $Y$, et al. Is it valuable and safe to perform reoperation for recurrent thymoma. Interact Cardiovasc Thorac Surg. 2015;21(4):526-31.

58. Wright CD. Pleuropneumonectomy for the treatment of Masaoka stage IVA thymoma. Ann Thorac Surg. 2006;82(4):1234-9.

59. Girard N, Mornex F, Van Houtte P, et al. Thymoma: a focus on current therapeutic management. J Thorac Oncol. 2009;4(1):119-26.

60. Fujii Y. Published guidelines for management of thymoma. Thorac Surg Clin. 2011:21(1):125-9. viii.

61. Evans TL. Emerging treatment options for patients with recurrent advanced thymic epithelial tumors. Onco Targets Ther. 2012;5:177-84.

62. Fornasiero A, Daniele O, Ghiotto C, et al. Chemotherapy for invasive thymoma: a 13-year experience. Cancer. 1991;68(1):30-3.

63. Loehrer Sr PJ, Kim K, Aisner SC, et al. Cisplatin plus doxorubicin plus cyclophosphamide in metastatic or recurrent thymoma: final results of an intergroup trial. The Eastern Cooperative Oncology Group, Southwest Oncology Group, and Southeastern Cancer Study Group. J Clin Oncol. 1994;12(6):1164-8.

64. Loehrer Sr PJ, Chen M, Kim K, et al. Cisplatin, doxorubicin, and cyclophosphamide plus thoracic radiation therapy for limited-stage nonresectable thymoma: an intergroup trial. J Clin Oncol. 1997;15(9):3093-9.

65. Loehrer Sr PJ, Yiannoutsos CT, Dropcho S, et al. A phase II trial of pemetrexed in patients with recurrent thymoma or thymic carcinoma. J Clin Oncol. 2006:24(18S):Abstract 7079.

66. Schmitt J, Loehrer Sr PJ. The role of chemotherapy in advanced thymoma. J Thorac Oncol. 2010;5(10 Suppl 4):S357-60.

67. Palmieri G, Merola G, Federico P, et al. Preliminary results of phase Ilstudy of capecitabine and gemcitabine (CAP-GEM) in patients with metastatic pretreated thymic epithelial tumors (TETs). Ann Oncol. 2010;21(6):1168-72.

68. de Bree $E$, van Ruth S, Baas $P$, et al. Cytoreductive surgery and intraoperative hyperthermic intrathoracic chemotherapy in patients with malignant mesothelioma or pleural metastases of thymoma. Chest. 2002;121(2):480-7.

69. De Bree E, van Ruth S, Schotborgh CE, et al. Limited cardiotoxicity after extensive thoracic surgery and intraoperative hyperthermic intrathoracic chemotherapy with doxorubicin and cisplatin. Ann Surg Oncol. 2007;14(10):3019-26.

70. Nakagiri T, Funaki S, Kadota Y, et al. Does gefitinib have effects on EGFR mutation-positive thymoma? -Case report of thymoma recurrence. Ann Thorac Cardiovasc Surg. 2014;20(Suppl):674-6.

71. Palmieri $G$, Marino $M$, Salvatore $M$, et al. Cetuximab is an active treatment of metastatic and chemorefractory thymoma. Front Biosci. 2007:12:757-61.

72. Farina G, Garassino MC, Gambacorta M, et al. Response of thymoma to cetuximab. Lancet Oncol. 2007;8(5):449-50.

73. Azad A, Herbertson RA, Pook D, et al. Motesanib diphosphate (AMG706), an oral angiogenesis inhibitor, demonstrates clinical efficacy in advanced thymoma. Acta Oncol. 2009;48(4):619-21.

74. Rajan A, Carter CA, Berman A, et al. Cixutumumab for patients with recurrent or refractory advanced thymic epithelial tumours a multicentre, open-label, phase 2 trial. Lancet Oncol. 2014;15(2):191-200.

75. Giaccone G, Rajan A, Berman A, et al. Phase II study of belinostat in patients with recurrent or refractory advanced thymic epithelial tumors. J Clin Oncol. 2011;29(15):2052-9.

76. Krenning EP, Kwekkeboom DJ, Bakker WH, et al. Somatostatin receptor scintigraphy with [111In-DTPA-D-Phe1]- and [123l-Tyr3]-octreotide: the Rotterdam experience with more than 1000 patients. Eur J Nucl Med. 1993;20(8):716-31.

77. Loehrer Sr PJ, Wang W, Johnson DH, et al. Octreotide alone or with prednisone in patients with advanced thymoma and thymic carcinoma: an Eastern Cooperative Oncology Group Phase II Trial. J Clin Oncol. 2004;22(2):293-9.

78. Zampa G. Targeting the therapy: octreotide in thymoma relapse. J Clin Oncol. 2007;25(18S):Abstract 18199.

79. Spaggiari L, Casiraghi M, Guarize J. Multidisciplinary treatment ofmalignant thymoma. Curr Opin Oncol. 2012;24(2):117-22.

80. Kunitoh $\mathrm{H}$, Tamura T, Shibata T, et al. A phase II trial of dose-dense chemotherapy, followed by surgical resection and/or thoracic radiotherapy, in locally advanced thymoma: report of a Japan Clinical Oncology Group trial (JCOG 9606). Br J Cancer. 2010;103(1):6-11.

81. Huang J, Rizk NP, Travis WD, et al. Feasibility of multimodality therapy including extended resections in stage IVA thymoma. J Thorac Cardiovasc Surg. 2007;134(6):1477-83.

82. Shin DM, Walsh GL, Komaki R, et al. A multidisciplinary approach to therapy for nonresectable malignant thymoma. Ann Intern Med. 1998;129(2):100-4.
83. Abtin F, Suh RD, Nasehi L, et al. Percutaneous cryoablation for the treatment of recurrent thymoma preliminary safety and efficacy. J Vasc Interv Radiol. 2015;26(5):709-14.

84. Kirkove C, Berghmans J, Noel H, et al. Dramatic response of recurrent invasive thymoma to high doses of corticosteroids. Clin Oncol (R Coll Radiol). 1992:4(1):64-6.

85. Koshio J, Tsukada H, Nagasawa Y, et al. Successful corticosteroid therapy of a recurrent thymoma with pure red cell aplasia. Nihon Kokyuki Gakkai Zasshi. 2007:45(11):879-83.

86. Taguchi T, Suehiro T, Toru K, et al. Pleural dissemination of thymoma showing tumor regression after combined corticosteroid and tacrolimus therapy. Eur J Intern Med. 2006;17(8):575-7.

87. Verley JM, Hollmann KH. Thymoma. A comparative study of clinical stages, histologic features, and survival in 200 cases. Cancer. 1985;55(5):1074-86.

88. Yano M, Sasaki $H$, Moriyama S, et al. Number of recurrent lesions is a prognostic factor in recurrent thymoma. Interact Cardiovasc Thorac Surg. 2011;13(1):21-4.

\section{Submit your next manuscript to BioMed Central and we will help you at every step:}

- We accept pre-submission inquiries

- Our selector tool helps you to find the most relevant journal

- We provide round the clock customer support

- Convenient online submission

- Thorough peer review

- Inclusion in PubMed and all major indexing services

- Maximum visibility for your research

Submit your manuscript at www.biomedcentral.com/submit

) Biomed Central 